\title{
Experience feedback from the IRSN's involvement in the FARMING post-accidental program
}

\author{
N. Reales, F. Gallay, B. Cessac and A. Oudiz \\ based on the work of the French FARMING Group \\ National Institute for Radiation Protection and Nuclear Safety (IRSN), \\ BP. 17, 92262 Fontenay-aux-Roses Cedex, France
}

\begin{abstract}
This paper is intended to present the experience feedback of the IRSN's involvement in the reflection on the management of a nuclear crisis. It sums up some results of the French FARMING working group, corresponding to the mobilization of a wide range of Agricultural Technical Institutes and to the appraisal of a compendium of agricultural countermeasures for the rehabilitation of rural contaminated territories in post accidental situations. Indeed, in France, since a few years, this problem has been almost exclusively considered by radiation protection experts, with no involvement of the other concerned actors. But according to the weight of the agro industrial sector in this country and to the problems related to the management of contaminated food in post accidental situations, the cooperation between radiation protection experts and agro industrial stakeholders appeared more and more necessary. Indeed, above all, farmers and other local actors would take a significant part to the rehabilitation actions from the short term to long term of a nuclear crisis period and then share the responsibilities of the crisis management. The working group has therefore opened new debates at the national level and valuable results have been obtained from the meetings at technical and strategic levels.
\end{abstract}

\section{INTRODUCTION}

In France, up to now, the preparation to accidental situations has been mainly focused on the early phase and on the management of the health protection. Although these preoccupations are preliminary, the actual situation in the Eastern countries after the Chernobyl accident raises the question of the long-term consequences management within a contaminated territory due to a diffuse radiological contamination.

First of all, beyond the radiological aspect of the early phase, the experience of this accident highlights that, in post accidental situation, the rehabilitation of decent sanitary conditions for the population would be closely related to the restoring of the economic and social dynamics on the contaminated territories. These dynamics would effectively be broken in the early phase, especially for the agricultural sector, because of imposed radiological controls and reluctance of urban consumers towards food products coming from the contaminated areas [1]. As France is, at the same time, the second world producer for food products, and one of the most important producer of electricity from nuclear power, the question of restoring agricultural areas would be highly sensitive, in this country, whatever the scale of the nuclear accident.

Secondly, the necessity appears to consider the early decisions keeping in mind their possible influence and/or limitation on the long-term rehabilitation capacities. Consequently, a reflection with the stakeholders on the consequences, the feasibility and the acceptability of the rehabilitation strategies should take place prior a "real situation" occurs, in Europe and particularly in France. 
That is the reason why, beyond its expertise during the emergency phase, IRSN is particularly interested in this subject. For example, since several years, IRSN is involved in international programs (EMRAS, THEMAS...), nuclear crisis practices at the international level (INEX 1,2 and 3...) and at the national level (so-called "Exercice Becquerel", severe PWR accident scenario...). Many scientific researches have been set up concerning, for example, the feasibility of the countermeasures or the transfer of radionuclides in the environment. In order to diffuse some radiation protection advises and prepare a nuclear crisis situation, a working program was initiated during the 1990's in collaboration with the National Federation of Agricultural Workers' Unions (FNSEA) and the French National Interprofessional Centre of the Dairy Economy (CNIEL). The participants realised a national handbook for agricultural stakeholders [2]. The necessity clearly appeared to wider develop this reflection.

\section{THE FARMING PROGRAM}

\subsection{The French FARMING Group}

The FARMING [3] program was funded by the European Commission Fifth Framework Programme (FP5), in order to create an European multidisciplinary network of stakeholder groups and to develop sustainable strategies for restoring contaminated rural areas. Five Member States (United Kingdom, Finland, Belgium, Greece and France) have been involved since the beginning of the project, each showing slight differences in their respective advancement in mobilizing stakeholders. In the UK, where the identification of stakeholders and their mobilization was already effective before the FARMING project starts, a working group was quickly created. In Finland, a smaller group also pre-existed was extended. New working groups were set up in Belgium, France and Greece. Each Member State was represented at the European level by a national coordinator, within a steering group, responsible for selecting topics, for discussion and for restoring the outcomes from national meetings via a web site.

In France, the Institute of Patrimonial Strategies (ISP) from the National Institute for Agronomy Paris-Grignon (INA P-G) co-ordinated the working-group, chaired by a representative from the Ministry for Agriculture. The French group put a lot of efforts in mobilizing a large panel of stakeholders who were not accustomed to tackle such problems. With the help of the ETHOS [4] Belarussian experience and with the support of some stakeholders from radiation protection, the reflection progressed on both strategic and technical aspects. This group was mainly composed of French agricultural authorities, representatives from agriculture, food industry and radiation protection experts.

\subsection{The Assessment Working Group}

The STRATEGY [5] Network, another European network of the FP5, aimed "to establish a holistic framework for the selection of optimal remediation strategies for long-term sustainable management of contaminated areas in Western Europe" [6]. Its members expressed their interest in asking FARMING network an assessment on the compendium of the rural countermeasures they had elaborated. The French FARMING Group used this opportunity to mobilize some agricultural stakeholders especially from the French Agricultural Technical Institutes (organizations of industrial research, technical support, experimentation, formation and information in agriculture which are specialized in one kind of agricultural production).

The diversity of the participants represented as best as possible the agricultural diversity of the French agriculture. Nevertheless, the participants didn't claim to represent neither their institute nor the other members of their agricultural sector. They only brought their point of view and the global stakes of their sector according to their sensibility and their technical knowledge. Therefore, it's important to notify the very interesting participation and the real motivation of all the voluntary participants. 


\section{ASSESSMENT OF THE STRATEGY'S AGRICULTURAL COUNTERMEASURES}

The Assessment Working Group selected ten of these countermeasures that were relevant according to the specificities of the French situation.

\subsection{Characteristics of the French food production and consequences on the nuclear crisis management}

In order to understand the results of the evaluation, it is necessary to remember the specificities of the French agricultural context. First of all, the French agricultural production is very diversified, with a lot of food product's types and specific production modes related to the diversity of agricultural soils and historical practices. Consequently, the main agricultural productions of the other FARMING Member States (i.e. intensive animals and cereals productions, Mediterranean productions like olives or wine for Greece) are also present in this country. This important diversity results, within the same country, in a variety of possible post accidental crisis scenarios, provided an accident at a given scale, and, consequently, in different strategic choices for post-accidental management.

Secondly, because of the recent food (BSE, dioxin...) and environmental (nitrates...) crisis due to intensive agriculture, consumer's expectation for food has changed, during the last years, from quantity to quality, authenticity and safety ("green tourism”, “direct selling”). This new demand represented a diversification opportunity for farmers concerning productions and activities. After an eventual nuclear accident, farmers would probably also implement rehabilitation of the agricultural environment, keeping in mind the consumers expectations towards health and environment protection.

\subsection{The first action in a food crisis period: Food bans}

In a food crisis period, the contamination of suspected food would be systematically measured. If the Councils Foods Intervention Levels (CFILs) [7], which insure a sanitary protection of the population, are exceeded, the food is banned and treated as waste. This countermeasure, if quickly applied, could have a potential to reassure consumers and retailers. Nevertheless, the French agricultural stakeholders pointed out the problem in putting a straight threshold between marketable and non-marketable: consumers would not accept to buy any contaminated foodstuffs, whatever their contamination level. However the definition of threshold would necessary to define what a contaminated product is and to delimit the intervention area.

\subsection{The question of the opportunity to produce final products whose radioactivity is lower than the CFILs}

Opposite to the "Contaminated food ban", another countermeasure could be the production of marketable products (< CFILs) from contaminated products. For instance, the "Dilution of milk" could have a very positive economic impact for the producers, in the short term, by allowing the sale of the initially contaminated milk. But the possible mistrust of the population towards the final products. Then, producers of both contaminated and marketable milk would support an economic prejudice. In more general terms, the processing of the contaminated products in products whose radioactivity is lower than the CFIL ("Salting of meat", "Select edible crop that can be processed"...) could be very costly in time, money and risk for the agro-industries, while they would finally generate products that the consumers would refuse anyhow. 


\subsection{Destructing or decontaminating the livestock?}

Two main strategies could be proposed from the STRATEGY's countermeasure, concerning the management of the livestock. The first one ("Alive monitoring" + "Clean feeding") would allow to maintain the livestock on the contaminated area and to continue local agricultural activities. But this option means a special supply of clean animal feeding. This could maybe raise questions in terms of feasibility for grazing livestock regions, especially if the accident happens in the spring or in the summer, even more as the scale of the accident would be important. For milk producing regions, where the cattle is often kept inside, their contamination could be maintained to rather low levels. Finally, this strategy would certainly need a well-prepared organisation and communication systems, and the definition of acceptable levels demarcating marketable food and food to be banned.

The second strategy ("Slaughter dairy cows" + "Incineration") could have a strong potential to reassure the consumers, with the feeling that the sanitary stakes are properly managed. However, it could need the building of new specific installations for the destruction and waste management in order to avoid the contamination of the slaughter plants situated outside the contaminated area or the transport of the contaminated material. The compensations of farmers for the livestock destruction should take into account all the expenses relating to the buying of a complete new livestock like has been defined after the BSE or the dioxin crisis. Consequently, this strategy clearly depends on the size of the concerned livestock.

Both strategies could have advantages and drawbacks and could be combined in space as far as the agriculture is concerned, and depending on the scale of the accident. But agricultural stakeholders have also pointed out another important factor in France: the status of "quality production" and the real sensitivity of the image. And a loss of image could be generated by mistrust toward food and could represent an important loss of income for these producers. In that case, destruction could be the only acceptable solution because agricultural stakeholders are inclined to think that consumers would not accept food products from the contaminated territories, especially for the labelled ones.

\subsection{How to decontaminate the soil?}

The French FARMING group studied two mains options of rehabilitating the agricultural soils: "Deep ploughing" and "Select alternative land use". Participants noticed that the countermeasure "Skim and burial ploughing" would be relatively unfeasible (cost / loss of fertility). As far as the countermeasure "Ploughing" is concerned, the technical feasibility could be good and the costs relatively low. The effectiveness on reducing the contamination of the next year crops would be quite satisfying. The main question concerns the irreversible integration of radionuclides in the soil with risks of further transfers toward the hydrographical network from soil to other compartments and uncontaminated areas. Moreover, this so called "Dilution" of the contamination would be under the responsibility of decision makers and of farmers but could be relatively badly accepted by the population. But, in case of a large-scale accident, this could also be the only feasible solution, the so treated agricultural territories being assigned to other activities than the previous agricultural ones called "alternative land use". For example linen and bio ethanol productions could respectively be processed in clothes or paper and bio-carburant. However, the French agricultural stakeholders think that the new products could have a strong potential to be rejected by the consumer. Alternatively, it could be possible to lay fallow the contaminated area with economical compensations.

\section{IRSN'S CONTRIBUTION AND BENEFIT}

As far as the evaluation of the STRATEGY's countermeasures, the FARMING Program allowed to lay the foundations and the conditions for initiating a wider reflection between agricultural and radiation protection stakeholders on the long-term management of rural contaminated areas in France. First of all, the construction of a common culture between actors was essential to start a constructive dialogue. 


\subsection{Construction of a common culture between agricultural and radiation protection stakeholders}

\section{- $\quad$ Construction of a common language}

On the one side, most of the French agricultural participants to FARMING felt the need of a first introduction to radioprotection's main concepts to make their involvement to the project easier. Then the available technical means for appraising the radiological situation from the early phase and for protecting populations as well as in a longer timescale for the rehabilitation of the agricultural environment were introduced by radiation protection experts and commented by the group.

On the other side, the main French characteristics for agriculture were summarised by agricultural participants, what has been very useful to the assessment of the countermeasures.

And finally, a new common language began step by step to emerge from the work, with the use of new words under a specific sense like "dilution”. This understanding made first discussions easier and could also avoid, in case of a crisis, a waste of time and some conflicts due to different interpretations of notions as the "dilution".

\section{- $\quad$ Sharing of national and international experiences}

The FARMING framework was an opportunity to share national and international experiences. For example, on one hand, the radiation protection participants could benefice of the agricultural stakeholders' experience concerning the sanitary crisis management. On the other hand, the Director of the Aube's Agricultural Office presented a concrete example concerning the management of a hypothetical nuclear accident in the "Nogent-sur-Seine" nuclear power plant and the different rehabilitation strategies studied with IRSN. At last, a member of the Dairy Industrial Association Limited (DIAL) presented to the French FARMING group the main results of a reflection on experience of the dairy sector concerning the management of contaminated dairy products in England.

\subsection{Improvement of the knowledge of the countermeasures implementation}

In case of a nuclear crisis, one of the IRSN's missions is to advise authorities in charge of the decision-making during the emergency and the post accidental phase. The FARMING Program was the opportunity to update the knowledge on the countermeasures implementation.

The main conclusions of the evaluation process on that subject were:

- Firstly, concerning the "technical feasibility", the countermeasures usually envisaged by the radiation protection experts are mainly focused on the northern agricultural context. Some of them are not technically feasible in France and little are suited to the Mediterranean agricultural context.

- Secondly, concerning their "acceptability” by public and farmers, the meetings confirmed the necessity to take not only the sanitary criteria into account and to consider the different stakes and points of view of each stakeholder.

- At last, this work underlines the necessity to prepare, in a non-crisis period, some rehabilitation strategies with different stakeholders and to take the consequences of the emergency countermeasures on the long-term reaction capacity into account.

\subsection{Identification of lacks and development of future partnerships}

\section{- $\quad$ The information means}

The FARMING Program was the opportunity for IRSN to evaluate and identify possible margins of improvement of the communication means. For example, it pointed out the necessity to improve decision-making support systems for the evaluation of countermeasures in real-time and to define some scenarios of accidental situations in order to give the necessary basic elements to initiate the reflection on the post-accidental strategies.

\section{- $\quad$ The scientific knowledge}


The dialogue allowed to identify some lacks of knowledge and the need of specific information especially about the consequences of the countermeasures implementation on the contamination risk of the soil and the hydrographical network after a ploughing. It also appears that information concerning some transfers of radionuclides to specific crops or final products was very poor. This first multidisciplinary work will consequently certainly generate futures scientific collaborations between agricultural and radiation protection stakeholders.

This exercise also highlighted a lack of information in several disciplines and the necessity to enlarge the panel of stakeholders. For example, the legislation, relating to the implementation of different countermeasures, was identified as a critical point to be considered in the context of a crisis, because rehabilitation strategies would be conditioned by national (and international) laws, but this question has been shelved by the group on account of the skilled actors absence. The costs of implementation of these countermeasures would be another key factor in the choice between the various rehabilitation strategies. But a cost assessment seems complicated because of identified lacks of knowledge on the local available means for rehabilitation and on compensation procedures.

\section{CONCLUSION}

Since several years, IRSN has been working on the management of contaminated areas after a nuclear accident, through several national and international programs. The FARMING Program was a good opportunity to deepen the collaboration and the reflection with agricultural stakeholders. Nevertheless, it clearly appears to the French FARMING participants that, in the event of a nuclear accident, France would not yet be fully operational to manage properly the long-term phase of the crisis. Consequently, a real need still exists in France to go on with such a reflection and to involve a wider panel of stakeholders. This is why it was decided to take part to the European Commission Sixth Framework Programme, EURANOS Integrated Project [8] on the questions of the rehabilitation of rural and urban territories. It will provide some funding of national projects associating agricultural and radiation protection stakeholders. Amongst these projects, one is the updating of a guide co-edited ten years ago by the former IPSN and two agricultural and dairy associations: FNSEA and CNIEL. This guide aimed at assisting the farmers to react efficiently in case of a nuclear accident and to implement appropriate early post-accidental countermeasures. Another one is the progressive involvement of agricultural stakeholders during the preparation of national nuclear crisis exercise.

\section{References}

[1] Bogdevitch, I., "Remediation Strategy and Practice on Agricultural Land Contaminated with 137Cs and 90Sr in Belarus”, EUROSAFE 2003, Environment and Radioprotection, p 83 to 96.

[2] "Agriculture, Environnement et Nucléaire: Comment réagir e cas d'accident» - FNSEA, CNIEL, IPSN (1991).

[3] FARMING (2000-2004): Food and Agricultural Restoration Management Involving Networked Groups, Nisbet, A.F., Mercer, J.A., Ollagnon, H., Pupin, V., Rantavaara, A., Hanninen, Vandecasteele R.C., Sombre, L., Ioannides, K. and Tzialla C., "Feedback on the first year stakeholder meetings in Belgium, Finland, France, Greece and UK”,(www.ec-farming.net).

[4] ETHOS (1996-2001): Rehabilitation of the Living Conditions in the Contaminated Territories after Chernobyl, (www.cepn.asso.fr/fr/ethos.html).

[5] STRATEGY (2000-2004): Sustainable Restoration and Long Term Management of Contaminated Rural, Urban and Industrial Ecosystems, involving five member states: United Kingdom, Denmark, Germany, Norway and Spain. (http://www.strategy-ec.org.uk/).

[6] Nisbet, A.F., Mercer, J.A., Hesketh, N., Andersson, K.G., Roed, J., Eged, K., Kis, Z., Alvarez-Farizo, B., Gil, J. M., Howard, B.J., Beresford, N. A., Hunt, J., Liland, A., ThØrring, H., Oughton, D., Voigt, G., "Compilation of a Countermeasure Compendium for Food Production Systems and Inhabited areas", EUROSAFE 2003, Environment and Radioprotection, p 61 to 69.

[7] EURATOM n²219/89 (07/18/1989).

[8] EURANOS: European Approach to Nuclear and Radiological Emergency Management, Integrated Project proposed for European Commission Sixth Framework Programme, (http://europa.eu.int/comm/research/fp6/euratom/firstcallresult_en.html). 